\title{
Induction of leaf senescence in Arabidopsis thaliana by long days through a light-dosage effect
}

\author{
Larry D. Noodén, Jennifer W. Hillsberg and Michael J. Schneider
}

\begin{abstract}
Noodén, L. D., Hillsberg, J. W. and Schneider, M. J. 1996. Induction of leaf senescence in Arabidopsis thaliana by long days through a light-dosage effect. - Physiol. Plant. 96: 491-495.

Given the influence of photoperiod on reproductive development and whole-plant senescence in monocarpic plants, one would suspect that leaf senescence in these plants might be under photoperiodic control. In Arabidopsis thaliana, which is monocarpic and also a nonobligate long-day (LD) plant, LDs $\left(16 \mathrm{~h}, 300 \mu \mathrm{mol} \mathrm{m} \mathrm{m}^{-2} \mathrm{~s}^{-1}\right)$ caused leaves to die earlier than did short days (SDs, $10 \mathrm{~h}$ ). Since leaf longevity was not paralleled by the reproductive development in the present study, the reproductive structures did not seem to be the primary controls of leaf senescence. The LD effect appeared to depend on the amount of light rather than on day length, for leaves given LDs at reduced light intensity $\left(180 \mu \mathrm{mol} \mathrm{m} \mathrm{m}^{-2} \mathrm{~s}^{-1}\right)$ lived longer than thase in LDs with full light. In addition, the higher light intensity promoted chlorophyll loss and anthocyanin accumulation in LDs. Thus, senescence of these leaves seems to be governed by light dosage rather than photoperiod. Light may play a natural role in promoting the senescence of A. thaliana leaves.
\end{abstract}

Key words - Arabidopsis thaliana, high irradiance response, leaf senescence, photoperiod, phototoxicity.

L. D. Noodén (corresponding author) and J. W. Hillsberg, Biology Dept, Natural Science Bidg, Univ. of Michigan, Ann Arbor, MI 48109-1048, USA; M. J. Schneider, Dept of Natural Science, Univ, of Michigan-Dearborn, Dearborn, MI 48128-1491, USA.

\section{Introduction}

Light appears to play important roles in controlling leaf senescence; however, light may promote senescence in some cases and retard it in others (Biswal and Biswal 1984). Given the quantitative and qualitative range of light that leaves normally experience and the different environments to which they must adapt, this range of responses is not surprising, but further analysis is needed to form a coherent picture of the light controls of leaf senescence. In many species, continuous darkness accelerates leaf senescence, and light may retard it at lower and moderate intensities. Prolonged retardation of leaf senescence by light requires intensities above the photosynthetic compensation point (Veierskov 1987). At high intensities, however, light may accelerate senescence, and this acceleration could be due to phototoxicity (Barber and Andersson 1992, Foyer et al. 1994). It can be ar- gued that many of the treatments, especially detachment of the leaf and/or exposure to continuous darkness, which have been used to study light control of leaf senescence are unnatural and may produce artificial responses (Noodén and Leopold 1978, Kar 1986, Noodén 1988a). Nonetheless, these treatments serve as useful probes of the controls of senescence (Noodén 1988a). Clearly, the influence of light is complex, and it extends beyond energy charge and nutritional effects, i.e. photosynthesis (Haber et al. 1969).

In addition to the quantitative light effects cited above, photoperiod controls many aspects of plant development (Vince-Prue 1975, Salisbury and Ross 1992), and it would also be expected to control senescence, either indirectly through regulation of reproductive development which often controls senescence (Noodén 1998b), or directly. A few reports (Schwabe 1970, Trippi and Brulfert 1973, Kar 1986, Schwabe and Kulkarni 
1987) indicate possible photoperiodic control of leaf senescence, and interestingly, all of these show delayed leaf senescence in short days (SDs) or accelerated senescence in long days (LDs). Similarly, tomato plants die when they are subjected to continuous light (Arthur et al. 1930, Highkin and Hanson 1954).

In the study reported here, we used Arabidopsis thaliana, which is a quantitative (nonobligate) LD plant (Napp-Zinn 1985), to determine whether LD induction of leaf senescence is a day-length or a light-dosage effect.

Abbreviations - LDFL, long day full light; LDRL, long day reduced light; SDFL, short day full light.

\section{Materials and methods \\ Plant culture}

Arabidopsis thaliana (L.) Heynh. cv. Columbia seeds were sown in cell packs containing artificial soil (Sunshine Mix 4, Fisons Horticultural, Inc., Mississauga, ON, Canada) consisting of peat moss, Perlite and bark $(3: 1: 0.5, \mathrm{v} / \mathrm{v} / \mathrm{v})$. Each cell measured $3.8 \times 3.8 \times 5 \mathrm{~cm}$ deep. These cell packs were moistened from below, chilled for $48 \mathrm{~h}$ at $5^{\circ} \mathrm{C}$ and then placed in SD ( 10 -h days with only cool-white fluorescent lights [Sylvania coolwhite VHO, F96T12/cw/VHO, GTE Products Corp., Sylvania Lighting Corp., Danvers, MA, USA] at 300

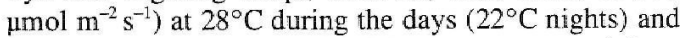
about $70 \%$ relative humidity. Plants were watered from below as needed and fertilized once a week with Peters water-soluble fertilizer (N:P:K, 20:20:20, w/w/w; Peters Fertilizer Products, Fogelsville, PA, USA) at $1.1 \mathrm{~g} \mathrm{l}^{-1}$. After the seedlings had formed four leaves, they were thinned to about 10 plants per cell and later at the sixleaf stage, to one plant per cell. The plants were then transplanted into square plastic pots $(7 \times 7 \times 6.4 \mathrm{~cm}$ deep) when the rosettes had reached approximately 3.5 $\mathrm{cm}$ in diameter.

\section{Treatments}

\section{Light treatment}

Leaves (including the two leaf-like cotyledons) were counted, and the 8th leaf on each plant was marked for reference. Three subsequent leaf cohorts (leaf number 14,17 and 20 , all \pm 1 ) were marked with a small drop of water-soluble typing correction fluid at intervals of about 4 days, and their dates of emergence were designated as the day when each new leaf reached $2 \mathrm{~mm}$ in length (Hensel et al. 1993). Care was taken to keep the marked leaves from being covered by other leaves. When about $75 \%$ of the plants had started to bolt (approximately 50 days after the seeds were planted), the light treatments were started. At this time, the first leaf cohort (leaf 14) was fully grown and the last (leaf 20) was almost fully grown. Ten plants were left in the SDs at full light (SDFL), $300 \mu \mathrm{mol} \mathrm{m}^{-2} \mathrm{~s}^{-1}$, and 20 were trans- ferred to LDs (16 h). Of the plants in LDs, 10 were shaded with a cheesecloth canopy (sides open for air circulation) to reduce the light intensity by about $40 \%$, to $180 \mu \mathrm{mol} \mathrm{m} \mathrm{m}^{-2} \mathrm{~s}^{-1}$ (LDRL), while 10 were left out at full light intensity, $300 \mu \mathrm{mol} \mathrm{m} \mathrm{m}^{-2} \mathrm{~s}^{-1}$ (LDFL). The plants given $16 \mathrm{~h}$ of light at reduced intensity (LDRL) received about the same amount of light energy as those given 10 $\mathrm{h}$ of full light intensity (SDFL). Light intensities were measured with a LI-COR (LI-COR, Inc., Lincoln, NB, USA) Li-189 light meter.

Measurement of leaf death and reproductive development

The collapse of homeostasis is the endpoint of senescence, and it represents a good measure of senescence (Noodén 1988a). Leaves were scored as dead when more than half of their surface area was flaccid or dried out. Usually, this final collapse of the leaf tissue proceeded rapidly, and it could be determined within 1 day. The leaf death experiments described here were run at least three times with similar results, and each data point is based on 10 leaves. The reproductive development data are based on at least seven whole plants.

The rate of reproductive development was measured for all plants as the dates when the first and 5 th fruits (siliques) reached $1 \mathrm{~cm}$ in length. The inflorescences from each plant were harvested when they were dead or nearly dead, dried in an oven $\left(10 \mathrm{~h}\right.$ at $\left.100^{\circ} \mathrm{C}\right)$ and weighed for dry weight data.

\section{Chlorophyll and anthocyanin measurements}

Chlorophyll levels in the leaves were measured nondestructively using a Minolta (Ramsey, NJ, USA) chlorophyll meter (SPAD-505), which allowed us to follow the same leaves over time. To calibrate the chlorophyll meter in terms of mg chlorophyll per g fresh weight of tissue, leaves with varying chlorophyll concentration and SPAD meter readings were weighed and the chlorophylls were extracted in $\mathrm{N}, \mathrm{N}$-dimethylformamide (DMF) as described by Canfield et al. (1995). The N,Ndimethylformamide extracts were measured at 647 and $664.5 \mathrm{~nm}$ on a Zeiss (Oberkochen, Germany) PMQ III spectrophotometer at a band width of $0.4 \mathrm{~nm}$. Total chlorophyll was calculated using the equations outlined by Inskeep and Bloom (1985).

To estimate the anthocyanin concentration, a single leaf was placed in $10 \mathrm{ml}$ of aqueous $25 \%$ (v/v) 1-propanol containing $0.01 \mathrm{M} \mathrm{HCl}$ and incubated for $24 \mathrm{~h}$ at $4^{\circ} \mathrm{C}$ in darkness. (Schneider and Stimson 1971). Samples were then boiled for $5 \mathrm{~min}$ and the absorbance at $535 \mathrm{~nm}$ was determined using the spectrophotometer described above.

\section{Results}

The survival curves (Fig. 1A) in which all three leaf cohorts for each treatment are pooled show a steady attrition of leaves; however, those treated with LDFL died 

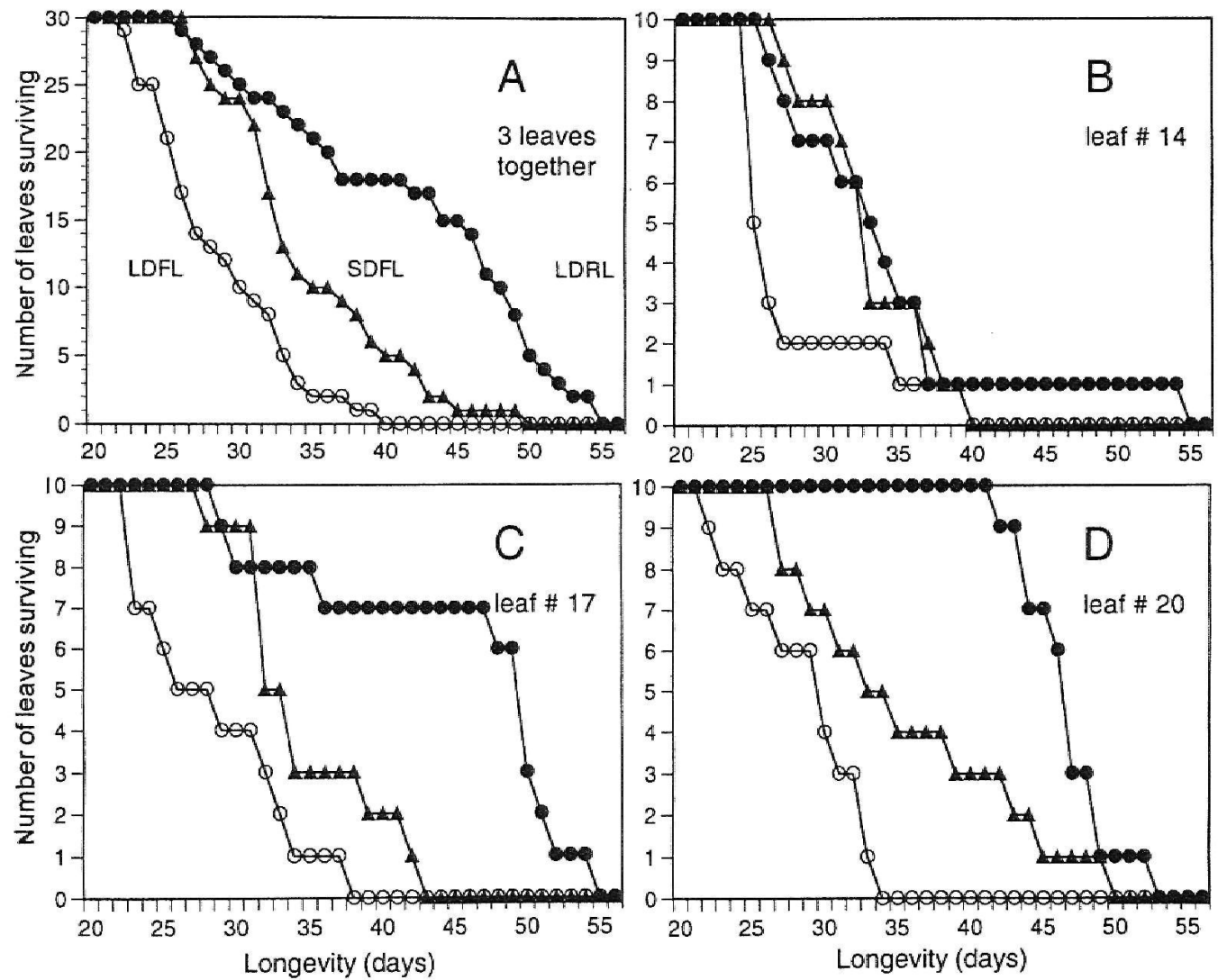

Fig. 1. The effects of day length and light intensity on leaf longevity. A. Three different leaves combined. B. Leaf cohort 1 (heaf 14 \pm 1 ). C. Leaf cohort 2 (leaf $17 \pm 1$ ). D. Leaf cohort 3 (leaf $20 \pm 1$ ). LDFL (O) long days, full light intensity; LDRL (C) long days, reduced light intensity; SDFL ( $\mathbf{\Delta})$ short days, reduced light intensity.

first, followed by those given SDFL and then LDRL. It is particularly significant that the leaves under SDFL died sooner than those given LDRL.

Taken separately (Tab. 1, Fig. 1B-D), the individual leaf cohorts showed similar longevity patterns differing mainly in their time frame. For cohort 1 (leaf 14, Fig. 1B), LDFL caused earlier death (average longevity 27.9 \pm 2.8 days, Tab. 1 ), while LDRL and SDFL treatments caused later death with no significant difference between LDRL and SDFL (average longevity $34.2 \pm 3.4$ and 33.2 \pm 1.5 days, respectively, Tab. 1 ). For cohort 2 (leaf 17 ,
Fig. 1C) and 3 (leaf 20, Fig. 1D), the leaves given LDFL again died considerably earlier than those given LDRL or SDFL. However, the leaves in cohorts 2 and 3 given SDFL senesced significantly sooner than those under LDRL (Tab. 1). In addition to the differences in the time frame, there may be some differences in the shapes of the longevity profiles (cf. LDFL vs LDRL for leaf 17 , Fig. 1C), but this requires further study.

The effect of light dosage on senescence of attached leaves as measured by chlorophyll loss is shown in Fig. 2A. Leaves under LDFL lost chlorophyll more rapidly

Tab. 1. Effects of day length and light intensity on leaf longevity. Values are means $\pm S E$.

\begin{tabular}{|c|c|c|c|}
\hline \multirow[t]{2}{*}{ Light treatments } & \multicolumn{3}{|c|}{ Average longevity (days) } \\
\hline & $\begin{array}{l}\text { Leaf cohort } 1 \\
\quad(\text { leaf } 14 \pm 1)\end{array}$ & $\begin{array}{c}\text { Leaf cohort } 2 \\
\text { (lleaf } 17 \pm 1)\end{array}$ & $\begin{array}{c}\text { Leaf cohort } 3 \\
\text { (leaf } 20 \pm 1)\end{array}$ \\
\hline Long days, full light intensity (LDFL) & $27.9 \pm 2.8$ & $28.6 \pm 3.0$ & $25.5 \pm 2.7$ \\
\hline Long days, reduced light intensity (LDRL) & $34.2 \pm 3.4$ & $45.1 \pm 4.2$ & $46.8 \pm 1.6$ \\
\hline Short days, full light intensity (SDFL) & $33.2 \pm 1.5$ & $34.8 \pm 2.7$ & $35.9 \pm 4.4$ \\
\hline
\end{tabular}



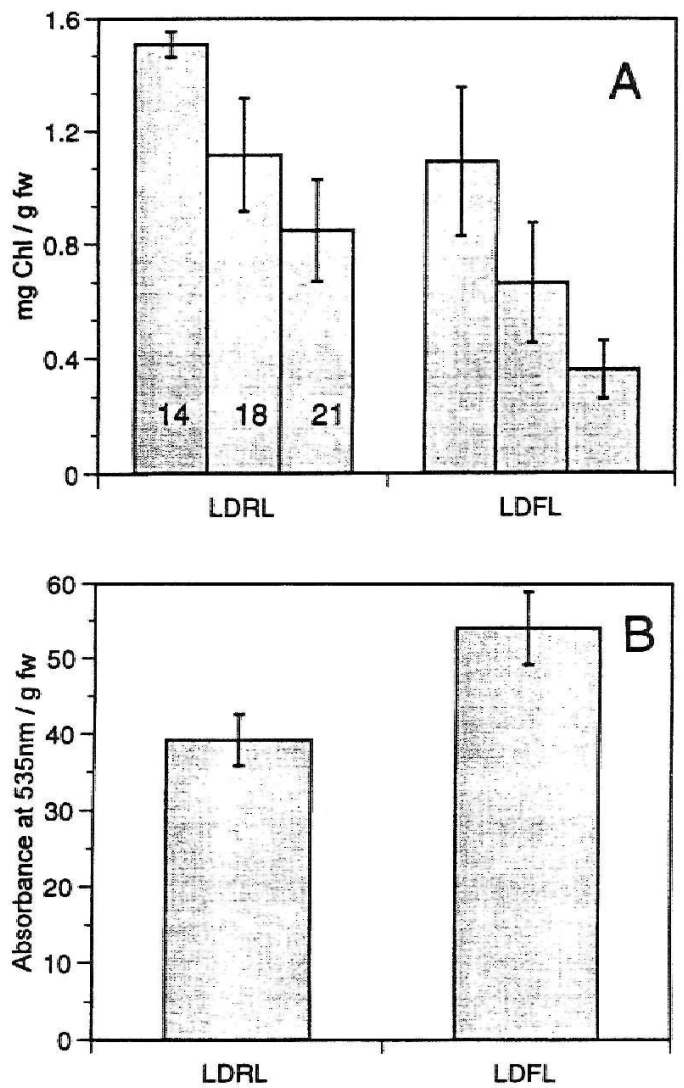

Fig. 2. The effects of fluorescent lamp (Fi) fluence rates and treatment duration on (A) chlorophyll and (B) anthocyanin concentrations in attached leaves. After 32 days under 10 -h days with fluorescent lights $\left(180 \mathrm{\mu mol} \mathrm{m} \mathrm{m}^{-2} \mathrm{~s}^{-1}\right)$, these plants were grown under fluorescent lamps for 16-h photoperiods at 180 (LDRL) or 300 (LDFL) jumol $\mathrm{m}^{-2} \mathrm{~s}^{-1}$. Chlorophyll concentrations were measured after 14,18 or 21 days of treatment, and anthocyanin concentrations were measured after 21 days. SE bars are shown.

than leaves on plants maintained under LDRL. Increases in the concentrations of anthocyanin in the leaves accompanied the more rapid loss of chlorophyll (Fig. 2B).

Because monocarpic (whole plant) senescence is often coupled with reproductive development (Noodén 1988b), we also measured the effects of the light treat- ments on reproductive development (Tab. 2). LDFL and LDRL produced more rapid development of the siliques than did SDFL. Although a visual assessment suggested that LDRL and SDFL produced larger inflorescences than LDFL, the difference in dry weight was not statistically significant (Tab. 2). LDRL also seemed to cause the inflorescences to branch more relative to those in LDFL; however, this effect was not significant in terms of dry weight.

\section{Discussion}

Arabidopsis thailana is a LD plant (Napp-Zinn 1985) and would typically flower during late spring and summer when the days are long. Since A. thaliana dies at the end of a single reproductive episode (monocarpy), the plant and its leaves normally senesce (monocarpic senescence) and die under LDs. It is, however, not an obligate LD plant, so it will eventually also flower and die under SDs, albeit with some delay. Given the correlative control commonly exerted by the reproductive structures on monocarpic senescence, one would suspect that they would also induce leaf senescence in $A$. thatiana. Interestingly, delayed flowering mutations (Hensel et al. 1993) and inflorescence-removal treatments (L. D. Noodén and A. E. Stewart, unpublished observations) do not significantly prolong the life of an individual leaf, which indicates that leaf senescence in A. thaliana is not controlled by the reproductive structures as it is in many other monocarpic species (Noodén 1988b). In keeping with its abbreviated life cycle, $A$. thaliana leaves are very short lived (28 to 47 days from initiation to death, Tab. 1) compared to other species, which may last up to 20 years (Molisch 1938, Kikuzawa 1989, Diemer et al. 1992).

What causes these leaves to die? Genetic factors are probably important, but environmental factors, including photoperiod, may also modulate senescence. In several cases (see Introduction), photoperiod may control leaf senescence, and, in all of these cases, LDs accelerate senescence compared with SDs. Arabidopsis thatiana leaves also senesce more rapidly in LDs.

To test whether the LD effect on $A$. thaliana leaves is due to photoperiod or to light dosage (e.g. phototoxicity), one group of plants was given LDs at reduced light intensity (LDRL) with the total light energy per day approximating that of SDFLs. The leaves subjected to LDRL lasted longer than those given SDFL indicating that this particular light effect is a light-dosage effect

Tab. 2. Effect of day length and light intensity on reproductive development. Values are means \pm SE.

\begin{tabular}{|c|c|c|c|}
\hline \multirow[t]{2}{*}{ Light treatments } & \multicolumn{2}{|c|}{ Days from start of treatments until } & \multirow{2}{*}{$\begin{array}{c}\text { Inflorescence dry } \\
\text { weight (g) }\end{array}$} \\
\hline & The first silique reached $1 \mathrm{~cm}$ & The 5 th silique reached $1 \mathrm{~cm}$ & \\
\hline Long days, full light intensity (LDFL) & $10.0 \pm 1.5$ & $12.9 \pm 2.4$ & $0.81 \pm 0.20$ \\
\hline Long days, reduced light intensity (LDRL) & $11.5 \pm 1.0$ & $14.1 \pm 1.0$ & $0.96 \pm 0.11$ \\
\hline Short days, full light intensity (SDFL) & $16.8 \pm 0.5$ & $18.8 \pm 0.6$ & $1.01 \pm 0.08$ \\
\hline
\end{tabular}


rather than a photoperiodic effect. The promotive effect of LDFL relative to LDRL on chlorophyll loss corroborates the importance of light dosage in promoting leaf senescence. Along with the decrease in chlorophyll, there was an increase in anthocyanin, which commonly occurs in response to high light intensities (Schneider and Stimson 1971, Sponga et al. 1986). Since $300 \mu \mathrm{mol}$ $\mathrm{m}^{-2} \mathrm{~s}^{-1}$ (SDFL and LDFL) is a low intensity compared to that of natural conditions, this light intensity effect may be quite significant in nature.

Because the reproductive structures play such an important role in the control of senescence of other monocarpic species (Noodén 1988b), we measured several parameters related to reproductive development even though two lines of evidence (see Discussion above) already indicate that reproductive structures may not control leaf senescence in A. thaliana. As would be expected for a LD plant, both LD treatments caused earlier silique development compared to $\mathrm{SD}$ treatments. We saw no significant difference in the timing of silique development between LDFL and LDRL, although there was a big difference in the timing of leaf senescence. Thus, the rate of reproductive development shows the traditional photoperiodic response, but it does not match the leaf senescence patterns. In addition, LDFL, LDRL and SDFL treatments do not yield inflorescences with significantly different dry weights. If anything, LDFL may produce a lower reproductive structure yield (dry weight) than do SDFL or LDRL. In other words, the more rapid senescence of the leaves in LDFL compared with that under LDRL and SDFL does not correlate with changes in the reproductive load. Therefore, these data provide additional evidence that leaf senescence is not closely tied to reproductive development in $A$. thatiana.

While our data on $A$. thaliana pertain to leaf longevity, whole-plant longevity seems to follow similar patterns here.

Acknowledgments - We gratefully acknowledge partial financial support from the University of Michigan Office of the Vice President for Research. We also thank Dr J. A. Teeri, University of Michigan Biological Station, for the loan of the Minolta SPAD-502 chlorophyll meter and Toby Hooker for help in calibrating the chlorophyll meter.

\section{References}

Arthur, J. W., Guthrie, J. D. \& Newell, J. M. 1930. Some effects of artificial climates on the growth and chemical composition of plants. - Am. J. Bot. 17: 416-482.

Barber, J. \& Andersson, B. 1992. Too much of a good thing: Light can be bad for photosynthesis. - Trends Biochem. Sci. 17:61-66.

Biswal, U. C. \& Biswal, B. 1984. Photocontrol of leaf senescence. - Photochem. Photobiol. 39: 875-879.

Canfield, M. R., Guiamét, J. J. \& Noodén, L. D. 1995. Alteration of soybean seedling development in darkness and light by the stay-green mutants $c y G$ and $G d_{1} d_{2}$ soybean by darkness and light. - Ann. Bot. 75: 143-150.

Diemer, M., Körner, Ch. \& Prock, S. 1992. Leaf life spans in wild perennial herbaceous plants: a survey and attempts at a functional interpretation. - Oecologia 89: 10-16.

Foyer, C. H., Lelandais, M. \& Kunert, K. J. 1994. Photooxidative stress in plants. - Physiol. Plant. 92: 696-717.

Haber, A. H., Thompson, P. J., Walne, P. L. \& Triplett, L. L. 1969. Nonphotosynthetic retardation of chloroplast senescence by light. - Plant Physiol, 44: 1619-1628.

Hensel, L. L., Grbic, V., Baumgarten, D. A. \& Bleecker, A. B. 1993. Development and age-related processes that influence the longevity and senescence of photosynthetic tissues in Arabidopsis. - Plant Cell 5: 553-564.

Highkin, H. R. \& Hanson, J. B. 1954. Possible interaction between light-dark cycles and endogenous daily rhythms on the growth of tomato plants. - Plant Physiol. 29: 301-302.

Inskeep, W. \& Bloom, P. R. 1985. Extinction coefficients of chlorophyll $a$ and $b$ in N,N-dimethylformamide and $80 \%$ acetone, - Plant Physiol. 77: 483-485.

Kar, M. 1986. The effect of photoperiod on chllorophyll loss and lipid peroxidation in excised senescing rice leaves. - J. Plant Physiol. 123: 389-393.

Kikuzawa, K. 1989. Ecollogy and evolution of phenological patterm, leaf longevity and leaf habit. - Evol. Trends Plants 3: $105-110$.

Molisch, H. 1938. The Longevity of Plants (H. Fulling, transl.). - Science Press, Lancaster, PA. pp. 95-103.

Napp-Zinn, K. 1985. Arabidopsis thaliana - In CRC Handbook of Flowering, Vol. 1 (A. Halevy, ed.), pp. 492-503. CRC Press, Boca Raton, FL. ISBN 0-8493-3911-1.

Noodén, L. D. 1988a. The phenomena of senescence and aging. - In Senescence and Aging in Plants (L. D. Noodén and A. C. Leopold, eds), pp. 1-50. Academic Press, San Diego, CA. ISBN 0-12-520920-7.

- 1988b. Whole plant senescence. - In Senescence and Aging in Plants (L. D. Noodén and A. C. Leopold, eds), pp. 391439. Academic Press, San Diego, CA. ISBN 0-12-520920-7.

- \& Leopold, A. C. 1978. Hormonal control of senescence and abscission. - In Phytohormones and Related Compounds, Vol. II (D. S. Letham, T. J. Higgins and P. B. Goodwin, eds), pp. 329-369. Elsevier, Amsterdam. ISBN 0-444-80054-9.

Salisbury, F. B. \& Ross, C. W. 1992. Plant Physiology, 4th Ed. Wadsworth Publ. Co., Belmont, CA. pp. 504-523 ISBN 0$534-15162-0$.

Schneider, M. J. \& Stimson, W. R. 1971. Contributions of photosynthesis and phytochrome to the formation of anthocyanin in turnip seedlings. - Plant Physiol. 48: 312-315.

Schwabe, W. W. 1970 . The control of leaf senescence in Kieinia articulata by photoperiod. - Ann. Bot. 34: 43-57.

- \& Kulkarni, V. J. 1987. Senescence-associated changes during long-day-induced leaf senescence and the nature of the graft-transmissible senescence substance in Kleinia articuIala. - J. Exp. Bot. 38: 1741-1755.

Sponga, F., Deitzer, G. F. \& Mancinelli, A. L. 1986. Cryptochrome, phytochrome, and the photoregulation of anthocyanin production under blue light. - Plant Physiol. 82: 952955.

Trippi, V. S. \& Brulfert, J. 1973. Organization of the morphophysiologic unit in Anagallis arvensis and its relation with the perpetuation mechanism and senescence. - Am. J. Bot. 60: $641-647$.

Veierskov, B. 1987. Irradiance-dependent senescence of isolated leaves. - Physiol. Plant. 71: 316-320.

Vince-Prue, D. 1975. Photoperiodism in Plants. - McGraw-Hill, Londion. ISBN 0-07-084048-2. 
This document is a scanned copy of a printed document. No warranty is given about the accuracy of the copy. Users should refer to the original published version of the material. 